\title{
PERSISTENCE OF MATERNALLY DERIVED ANTIBODIES IN CALVES TO VACCINATION AGAINST FOOT AND MOUTH DISEASE
}

\author{
L. Akhter ${ }^{1}$, M. S. Rahman ${ }^{1}$, M. G. Uddin ${ }^{2}$, M. B. $\operatorname{Rahman}^{3}$, A. K. M. A. Rahman ${ }^{1}$, M. H. Rahman ${ }^{2}$, F. W. \\ Nahat ${ }^{1}$ and M. T. Islam ${ }^{1 *}$
}

${ }^{1}$ Department of Medicine, Faculty of Veterinary Science, Bangladesh Agricultural University, Mymensingh-2202, Bangladesh; ${ }^{2}$ Bangladesh Livestock Research Institute, Savar, Dhaka; ${ }^{3}$ Department of Microbiology and Hygiene, Faculty of Veterinary Science, Bangladesh Agricultural University, Mymensingh-2202, Bangladesh

\begin{abstract}
This study aimed to know the level of maternally derived antibody (MDA) titer in calves born to cows vaccinated with inactivated trivalent (type $\mathrm{O}, \mathrm{A}$ and Asia 1) Foot and Mouth disease vaccine. Three groups of calves (10 calves in each group) of different age were randomly selected from two organized farms from Savar Upazilla of Bangladesh where the dams are routinely vaccinated with trivalent FMD vaccines. Blood samples were collected from these selected calves in six occasions five weeks apart and sera $(n=180)$ were tested for antibody titer against FMDV by using liquid phase blocking ELISA (LPBELISA) test. The test is based upon specific blocking of the FMDV antigen in liquid phase by antibodies in the test serum sample. Protective level (PI value >50) of maternal antibody against FMDV was found in serum of calves up to the age of 2223 wks (above five months) and decreased below protective level (PI value <50) at 27-28 weeks (above 6 months) of age. Irrespective of vaccine types, male calves had slightly higher level of MDA than that of female calves and PI values were comparatively higher against serotype $\mathrm{O}$ than the other two serotypes (A and Asia 1). Calves born to vaccinated dams could be vaccinated for first time after five months of their birth to lower the incidence of foot and mouth disease.
\end{abstract}

Keywords: Foot and mouth disease, maternally derived antibody, LPB-ELISA

\section{INTRODUCTION}

Foot and Mouth disease (FMD) is the most infectious of all animal diseases and it is considered the most economically important disease of farm animals since it causes significant decreases in livestock productivity and trade in livestock products (Domingo et al., 2002). In Bangladesh most of the people (80\%) depend on agriculture, mainly on livestock rearing. But there are many diseases which hamper the production of livestock. Among these FMD is the most detrimental and it is considered as one of the major constraints for livestock development in Bangladesh (Zinnah et al., 2010). It is a highly infectious disease of ungulates primarily of cattle, sheep, goats and pigs. The etiological agent, FMD virus (FMDV), is a single stranded RNA virus of the Aphthovirus genus, family Picornaviridae occurring in seven serotypes (O, A, C, Asia-1, SAT1, SAT2, and SAT3) and more than 65 subtypes (Kitching et al., 1998). Infection with FMDV causes an acute disease that spreads very rapidly and is characterized by fever, lameness and vesicular lesions on the feet, tongue and teats, with high morbidity but low mortality (Grubman and Baxt, 2004). Although FMD rarely causes death in adult animals, mortality rates are very high in young animals (Doel, 1996). In Bangladesh the disease is endemic in nature. The serotypes of FMD virus circulating in Bangladesh are predominantly O (Loth et al., 2011; Nandi et al., 2015), A and Asia 1 (Hossen et al., 2014). Serotype C is very rare and after 1996 there was no report of this serotype in Bangladesh (Chowdhury et al., 1996; Kadir and Ahmed, 2014). In Bangladesh, FMD causes annual loss approximately US\$125 million declining meat and milk productivity of cattle (Rahman et al., 2012). Among ruminants cattle are most susceptible (Chowdhury et al., 1996; Hawlader et al., 2004). Although the disease is less susceptible to young calves compared to adult cattle (Chowdhury et al., 1996; Mannan et al., 2009) the disease is fatal to calves causing 50 to $100 \%$ calf mortality (Brooksby, 1986; Webster and Granoff, 1994; Zinnah et al., 2010). In countries like Bangladesh the containment and control of FMD relies predominantly on vaccination. Calves bore to vaccinated cows usually possess maternal antibodies against FMDV in their serum for 2-6 months (Shankar and Uppal, 1982; Madhanmohan et al., 2009). This maternally derived antibody (MDA) provides immediate protection against infection with FMD virus, but also interferes with the development of active immunity following vaccination (Kitching and Salt, 1995). For an effective vaccination program, the

*Corresponding e-mail address: taohid@bau.edu.bd 


\section{Akhter and others}

information on duration of maternal immunity in calves is very essential. This study aims to evaluate the persistence of maternally derived antibody in calves born to immunized mother.

\section{MATERIALS AND METHODS \\ Study calves}

Three groups of calves were selected on the basis of their age from two organized farms located in Savar Upazilla of Dhaka district. The calves of group-1 were of crossbreed and calves of group-2 and group- 3 were of indigenous breed.

Group 1: Ten calves were randomly selected from one organized farm (Farm-1) aged between 2 to 3 weeks whose' dams were vaccinated during 4 to 5 months of pregnancy with a trivalent inactivated FMD vaccine (Vaccine-1).

Group 2: Ten calves aged between 7 to 8 weeks were selected randomly from another organized farm (Farm-2) whose' dams were vaccinated during 4 to 5 months of pregnancy with another trivalent commercial FMD vaccine (Vaccine-2).

Group 3: Ten calves aged between 18-39 weeks (4-9 months) were selected randomly from organized farm-2 whose' dams were vaccinated at 6 to 7 months of pregnancy with trivalent inactivated FMD vaccine (Vaccine-2).

\section{Blood samples}

Blood samples were collected from calves of Group 1 and Group 2 at every 5 weeks interval for six consecutive occasions and from Group 3 calves, blood samples were collected for a single occasion as those were waiting for vaccination for the first time. After collection of blood sample in every occasion, sera were separated by centrifugation at $1300 \mathrm{rpm}$ for 10 minutes and preserved at $-20^{\circ} \mathrm{C}$ until tested.

\section{Liquid-Phase Blocking ELISA (LPB-ELISA)}

All the sera samples were tested for antibody against FMDV serotypes $\mathrm{O}$, A and Asial by performing LiquidPhase Blocking ELISA (WRL, Pirbright, Surry, UK) as per manufacturer's instruction. For each serotype separate tests were done. The diagnostic threshold for this assay is at 50\% inhibition (50 PI). If percentage of inhibition (PI) value found above 50, the serum is protective and if PI value falls below 50, the serum is considered nonprotective against FMD (Table 1).

Table 1. Percentage of Inhibition (PI) values \& their interpretation for LPB-ELISA test

\begin{tabular}{ll}
\hline Percentage of Inhibition (PI) values & Interpretation \\
\hline $100-85$ & Strong Positive Serum \\
$84-50$ & Moderate Positive Serum \\
$49-0$ & Negative \\
\hline
\end{tabular}

\section{RESULTS AND DISCUSSION}

In all the three groups maternally derived antibodies (MDA) remained at protective level (PI value $>50$ ) upto the age of 22-23 wks and decreased below protective level (PI value <50) at 27-28 weeks (above 6 months) of age. This findings support the finding of Madhanmohan et al. (2009), who stated that MDA titers are likely to persist for 4-5 months of age in calves. Periolo et al. (1993) and Auge de Mello et al. (1989) also opined that young calves are the mandatory candidate for FMD vaccination at 4-5 months after birth when they lose passive immunity. Irrespective of vaccine types, male calves had slightly higher level of MDA than that of female calves and PI values were comparatively higher against serotype $\mathrm{O}$ than the other two serotypes (A and Asia 1). The MDA titer level in calves of Group 3 was almost similar as to calves of Groups 1 and 2 (data not shown). It was found that there was no noticeable MDA titer in calves aged above 7 months. This finding is in agreement with 
the findings of Kitching (2002) and Shankar and Uppal (1982). The findings suggest that calves born to vaccinated dams are needed to be vaccinated for the first time after five months of their birth.

Table 2. Persistence of MDA in calves born to vaccinated dam ${ }^{\#}$ (Vaccine -1)

\begin{tabular}{llllllll}
\hline FMDV & & \multicolumn{5}{c}{ PI values (Mean \pm SD) } \\
\cline { 3 - 7 } Serotypes & & $2-3$ wks & $7-8$ wks & $12-13$ wks & $17-18$ wks & $22-23 w k s$ & $27-28$ wks \\
\hline All & O & $94.34 \pm .45$ & $93.03 \pm .75$ & $91.13 \pm 1.20$ & $82.69 \pm 6.02$ & $70.66 \pm 5.24$ & $51.14 \pm 4.25$ \\
calves & A & $91.59 \pm 3.45$ & $86.26 \pm 3.46$ & $83.23 \pm .3 .70$ & $69.27 \pm 9.02$ & $60.51 \pm 6.09$ & $42.84 \pm 8.76$ \\
& Asia1 & $90.9 \pm 1.52$ & $88.66 \pm 2.05$ & $87.27 \pm 3.75$ & $76.93 \pm 4.49$ & $71.27 \pm 8.49$ & $40.97 \pm 12.15$ \\
Male & O & $94.39 \pm .42$ & $93.11 \pm .77$ & $90.95 \pm 1.30$ & $83.96 \pm 5.06$ & $73.65 \pm 5.06$ & $52.96 \pm 2.85$ \\
& A & $93.17 \pm 4.52$ & $87.64 \pm 3.09$ & $83.67 \pm 3.83$ & $71.71 \pm 7.43$ & $62.64 \pm 4.60$ & $43.85 \pm 8.69$ \\
& Asia1 & $90.25 \pm 1.80$ & $87.83 \pm 2.28$ & $87.14 \pm 3.94$ & $78.72 \pm 3.80$ & $75.4 \pm 9.75$ & $43.03 \pm 11.24$ \\
Female & O & $94.29 \pm .53$ & $92.94 \pm .81$ & $91-32 \pm 1.21$ & $81.41 \pm 7.20$ & $67.66 \pm 7.20$ & $49.32 \pm 5.31$ \\
& A & $90.01 \pm .30$ & $84.87 \pm 3.55$ & $82.79 \pm 3.97$ & $66.83 \pm 10.63$ & $58.37 \pm 7.14$ & $41.83 \pm 9.72$ \\
& Asia1 & $91.54 \pm .97$ & $89.50 \pm 1.58$ & $84.40 \pm 4.02$ & $75.14 \pm 4.79$ & $67.14 \pm 4.94$ & $38.91 \pm 13.97$ \\
\hline
\end{tabular}

\#Dams were vaccinated against FMD at 4 to 5 months of pregnancy.

Table 3. Persistence of MDA in calves born to vaccinated dam ${ }^{\#}$ (Vaccine-2)

\begin{tabular}{llllllll}
\hline FMDV & & \multicolumn{5}{c}{ PI values (Mean \pm SD) } \\
\cline { 3 - 7 } Serotypes & & $7-8$ wks & $12-13$ wks & $17-18$ wks & $22-23 w k s$ & $27-28 w k s$ & $32-33$ wks \\
\hline All & O & $88.93 \pm 4.21$ & $86.65 \pm 4.92$ & $79.52 \pm 5.19$ & $67.11 \pm 8.16$ & $46.22 \pm 9.63$ & $41.64 \pm 6.71$ \\
Malves & A & $84.32 \pm 10.83$ & $68.7 \pm 5.53$ & $62.7 \pm 8.35$ & $51.17 \pm 7.30$ & $42.42 \pm 0.38$ & $29.91 \pm 9.72$ \\
& Asia1 & $84.6 \pm 6.36$ & $78.82 \pm 6.57$ & $75.19 \pm 9.15$ & $58.96 \pm 7.34$ & $41.55 \pm 10.86$ & $29.78 \pm 11.01$ \\
& O & $90.83 \pm 3.48$ & $89.02 \pm .45$ & $83.19 \pm 4.91$ & $74.16 \pm 4.97$ & $48.78 \pm 10.92$ & $44.69 \pm 6.50$ \\
& A & $84.53 \pm 8.44$ & $69.91 \pm 6.23$ & $64.14 \pm 9.20$ & $55.22 \pm 4.89$ & $47.71 \pm 8.37$ & $35.42 \pm 6.05$ \\
Female & Asia1 & $89.67 \pm 5.04$ & $83.98 \pm .89$ & $81.09 \pm 7.97$ & $64.32 \pm 4.19$ & $44.98 \pm 11.31$ & $35.22 \pm 12.57$ \\
& O & $87.03 \pm 4.32$ & $84.28 \pm 6.34$ & $75.85 \pm 1.66$ & $61.27 \pm 4.61$ & $43.66 \pm 5.06$ & $39.05 \pm 6.51$ \\
& A & $84.10 \pm 13.87$ & $67.48 \pm 5.12$ & $61.27 \pm 8.18$ & $47.12 \pm 7.42$ & $37.13 \pm 10.12$ & $24.39 \pm 9.99$ \\
& Asia1 & $79.54 \pm 1.19$ & $73.66 \pm 5.45$ & $69.30 \pm 6.20$ & $53.61 \pm 5.64$ & $38.12 \pm 10.41$ & $24.35 \pm 6.42$ \\
\hline
\end{tabular}

\#Dams were vaccinated against FMD at 4 to 5 months of pregnancy.

\section{ACKNOWLEDGEMENTS}

The authors acknowledge the financial assistance from a GoB funded project of Bangladesh Livestock Research Institute (BLRI) entitled "Research on Foot and Mouth Disease (FMD) and Peste des Petits Ruminants (PPR) in Bangladesh."

\section{REFERENCES}

1. Auge De Mello P, Gomes I and Bahnemann HC (1989). The vaccination of young cattle with an oil adjuvant footand-mouth disease vaccine. Bol Centre Panama Fiebre aftosa 55: 9 -14.

2. Brooksby JB (1986). Portraits of viruses: foot-and-mouth disease: an introduction. Scientific and Technical Review Office International des Epizooties 5: 257-263.

3. Chowdhury SMZH, Rahman MF, Rahman MB and Rahman MM (1996). Strains of Foot-and Mouth-Disease virus in different districts of Bangladesh. Asian-Australasian Journal of Animal Sciences 9: 315-317.

4. Doel TR (1996). Natural and vaccine induced immunity to foot-and-mouth disease. Scientific and Technical Review Office International des Epizooties 15: 883-911.

5. Domingo E, Baranowski E and Escarmis S (2002). Foot-and-mouth disease. Microbiology and Infectious Disease 25: 297-308.

6. Grubman MJ and Baxt B (2004). Foot-and-mouth disease. Clinical Microbiology Review 17: 465-493.

7. Hossen ML, Ahmed S, Khan MFR, Rahman MT, Saha S, Nazir KHMNH, Rahman M, Islam MA and Rahman MB (2014). Typing of Foot and Mouth Disease Virus Circulating in Bangladesh by Reverse Transcription Polymerase Chain Reaction. Journal of Veterinary Advances 4: 778-785. 


\section{Akhter and others}

8. Howlader MMR, Mahbub-E-Elahi ATM, Habib S, Bhuyian MJU, Siddique MAB, Hai MA and Hossain MG (2004). Foot and Mouth Disease in Baghabari Milk Shed area and its economic loss in Bangladesh. Journal of Biological Science 4: 581-583.

9. Kadir A and Ahmed S (2014). Identification of different serotypes of Foot and Mouth Disease Virus from Sylhet district, Bangladesh; by adoption and application of RT-PCR and mRT-PCR. International Journal of Natural Sciences 4: 28-34.

10. Kitching RP (2002). Clinical variation in foot and mouth disease: cattle. Scientific and technical Review Office International des Epizooties 21:499-504.

11. Kitching RP (1998). A recent history of foot and mouth disease. Journal of Comparative Pathology 118: 89-108.

12. Kitching RP and Salt JS (1995). The interference by maternally-derived antibody with active immunization of farm animals against foot-and-mouth disease. British Veterinary Journal 151: 379-389.

13. Loth L, Osmani MG, Kalam MA, Chakraborty RK, Wadsworth J, Knowles NJ, Hammond JM and Benigno C (2011). Molecular Characterization of Foot-and Mouth Disease Virus: Implications for Disease Control in Bangladesh. Transboundary and Emerging Diseases 58: 240-246.

14. Madhanmohan M, Tresamol PV and Saseendranath MR (2009). Immune response in goats to two commercial foot-and-mouth disease vaccines and the assessment of maternal immunity in their kids. Transboundary and Emerging Diseases 56: 49-53.

15. Mannan MA, Siddique MP, Uddin MZ and Parvez MM (2009). Prevalence of foot and mouth disease (FMD) in cattle at Meghna upazila in Comilla in Bangladesh. Journal of Bangladesh Agricultural University 7: 317-319.

16. Nandi SP, Rahman MZ, Momtaz S, Sultana M and Hossain MA (2015). Emergence and Distribution of Foot-andMouth Disease Virus Serotype A and O in Bangladesh. Transboundary and Emerging Diseases 62: 328-31.

17. Periolo OH, Seki C, Grigera PR, Robiolo B, Fernandez G, Maradei E, Aloia R and La Torre JL (1993). Large scale use of liquid phase blocking sandwich ELISA for the evaluation of protective immunity against aphthovirus in cattle vaccinated with oil-adjuvant vaccines in Argentina. Vaccine 11: 754-760.

18. Rahman A, Arif MA, Sabbir SM, Alam A, Khatun F, Hossain S, Hossain M, Zaman F, Sultana M and Hossain MA (2012). FMD virus genotyping tool. Journal of Food Science and Engineering 2: 522.

19. Shankar H and Uppal PK (1982). Immune response of newborn calves to vaccination with foot and mouth disease vaccine. Scientific and Technical Review Office International des Epizooties 1: 403-414.

20. Webster RG and Granoff A (1994). Foot-and-mouth disease viruses. Encyclopedia of virology, Academic Press, London 3: 488-496.

21. Zinnah MA, Islam MT, Rahman MM, Hossain MT, Zinnah MA, Bari MR, Haque MH, Khan MSR and Islam MA (2010). Standardization of Multiplex Reverse Transcription Polymerase Chain Reaction and typing of Foot-AndMouth disease virus prevalent in Bangladesh. Bangladesh Journal of Veterinary Medicine 8: 149-155. 